\title{
Capturing and promoting the autonomy of capacitous vulnerable adults
}

\author{
Jonathan Lewis
}

Institute of Ethics, Dublin City University, Dublin, Ireland

\section{Correspondence to} Dr Jonathan Lewis, Institute of Ethics, Dublin City University, Dublin IE 9, Ireland: jonathan.lewis@dcu.ie

Received 29 August 2020 Revised 27 October 2020 Accepted 21 November 2020 Published Online First 21 December 2020
D Check for updates

(C) Author(s) (or their employer(s)) 2021. No commercial re-use. See rights and permissions. Published by BMJ.

To cite: Lewis J. J Med Ethics 2021;47:e21.

\section{ABSTRACT}

According to the High Court in England and Wales, the primary purpose of legal interventions into the lives of vulnerable adults with mental capacity should be to allow the individuals concerned to regain their autonomy of decision-making. However, recent cases of clinical decision-making involving capacitous vulnerable adults have shown that, when it comes to medical law, medical ethics and clinical practice, vulnerability is typically conceived as opposed to autonomy. The first aim of this paper is to detail the problems that arise when the courts and healthcare practitioners respond to the vulnerability of capacitous adults on the basis of such an opposition. It will be shown that not only does the common law approach to vulnerability fail to adequately capture the autonomy of capacitous vulnerable adults, the conception of vulnerability and autonomy in oppositional terms leads to objectionably paternalistic healthcare responses that undermine the autonomy of vulnerable patients as well as clinical and legal interventions that violate their autonomy. In response, the second aim of this paper is to show that the concepts of autonomy and vulnerability are necessarily entwined and, on that basis, the focus should be on promoting the autonomy of capacitous vulnerable adults where possible. In order to make this case, the paper explains the limitations of standard approaches to the autonomy of vulnerable adults and, in their place, offers a conception of legitimate, self-authorised autonomy that is fundamentally dependent on intersubjective practices of recognition.

\section{INTRODUCTION}

In England and Wales, the Mental Capacity Act ('MCA') 2005 formalised and extended previous developments at common law. In sections 2 (1) and 3 (1), the Act makes explicit certain standards by which an adult can be judged to lack mental capacity at a time when a decision, including a decision regarding their care or medical treatment, needs to be made. In addition, it clarifies the procedures for making a decision on behalf of an adult judged to lack the mental capacity to make that decision. Prior to the MCA 2005, the means by which the High Court could intervene in decision-making situations involving adults deemed to lack mental capacity was by exercising its 'inherent jurisdiction', which was extended in 1990 by a judgment made by the House of Lords to cover decisions in the 'best interests' of individuals lacking capacity. ${ }^{1}$ More importantly, even before the MCA 2005 came into force on 1 October 2007, the High Court had already begun to exercise its inherent jurisdiction in order to safeguard adults deemed to be 'vulnerable', whether or not they lacked capacity to make a decision regarding the matter in question. ${ }^{2}$

Since the establishment of MCA 2005's decisionmaking procedures for adults lacking mental capacity, there has been a debate about whether the High Court's inherent jurisdiction will survive. ${ }^{1}$ That said, for the past 13 years, judgments relating to vulnerable adults with mental capacity have shown that the inherent jurisdiction has not been entirely superseded by the MCA 2005. ${ }^{\mathrm{i}}$ The point is that the High Court has broadened the scope of its inherent jurisdiction beyond mentally incapacitated adults to include capacitous vulnerable adults, that is, those adults with mental capacity who are deemed to be at risk from the actions of other people. ${ }^{3}$ As a risk-based, protective response to vulnerability, ${ }^{1}$ the inherent jurisdiction continues to encompass those individuals not covered by the Court of Protection's jurisdiction and the MCA 2005's specific procedures relating to the principle of 'best interest' due to the fact that such individuals are considered to satisfy the test for mental capacity detailed in sections 2 and 3 of the Act. Although applications under the inherent jurisdiction have largely pertained to marriage, contact and residence, ${ }^{2}$ the High Court has considered applications that relate specifically to healthcare and medical treatment decisions.

According to the High Court, the primary purpose of the inherent jurisdiction as it relates to vulnerable adults with mental capacity is to 'allow the individual to be able to regain their autonomy of decision-making'. ${ }^{4}$ The premise is that capacitous vulnerable adults are deemed to be 'externally' and 'objectively' at risk to threats to their autonomy. ${ }^{2}$ Specifically, a capacitous adult is taken to be vulnerable at law when they are judged to be at risk of constraint, coercion or undue influence or otherwise 'incapacitated' or 'disabled from giving or expressing a real and genuine consent'. ${ }^{5}$ In order to restore autonomy to a decision-making situation that concerns a vulnerable adult with capacity, interventions by the High Court attempt to either alleviate the vulnerability of the adult in question or remove vulnerability from the decision-making

\footnotetext{
${ }^{\mathrm{i}}$ The question of whether the inherent jurisdiction has survived so as to intervene in matters relating to vulnerable adults who are deemed to have mental capacity has, seemingly, been answered by the decision of the Court of Appeal in $D L v A$ Local Authority [2012]. ${ }^{3}$ Also see London Borough of Wandsworth $v M$ \& Ors [2017] EWHC 2435 (Fam), [2018] 1 FLR 919; Southend-on-Sea Borough Council v Meyers [2019] EWHC 399 (Fam).
} 
situation altogether by granting decision-making authority to a designated non-vulnerable third party.

The High Court has suggested that, in the first instance, it will seek to exercise the inherent jurisdiction so as to facilitate a process of 'unencumbered decision-making'. ${ }^{36}$ According to the judgments in which this term is employed, such a process is considered to be a 'facilitative, rather than dictatorial, approach, ${ }^{3}$ one that, following Macur J (at (62)), attempts to alleviate vulnerability by supporting capacitous vulnerable adults to make decisions 'free of external pressure or physical restraint'. ${ }^{6}$ Elaborating, Bodey J (at (79)) states that 'the purpose, in respect of a capacitated but vulnerable adult, is to create a situation where he or she can receive outside help free of coercion, to enable him or her to weigh things up and decide freely what he or she wishes to do' ${ }^{7}$ However, when the High Court has focused on duties of protection rather than the facilitation of 'unencumbered decision-making', the inherent jurisdiction has been exercised in order to deny capacitous vulnerable adults their decision-making authority. ${ }^{8}$

It seems that the justification for both approaches stems from the principle that, when decisions need to be made regarding medical treatment or care, legally valid consent requires that it be given voluntarily. However, on the basis that legal precedent has established vulnerability in terms of the risks of being constrained, coerced, unduly influenced or otherwise unable to give or express real and genuine consent, ${ }^{\mathrm{ii}}$ the model of informed consent excludes those who have been identified as vulnerable precisely because the voluntariness of their decisions is at risk. Thus, the courts' attempts to alleviate vulnerability by facilitating 'unencumbered decision-making' should be viewed as a process aimed at supporting capacitous vulnerable adults to fulfil the typical conditions required for informed consent.

As this paper will go on to demonstrate, there are three problems with such responses to vulnerability in medical decisionmaking contexts. First, the facilitation of 'unencumbered decision-making' should not be equated with the restoration of autonomy of decision-making. Second, the primary legal concern with restoring patient autonomy can be too readily bypassed in healthcare and common law situations in favour of a narrow set of duties to protect the welfare of capacitous vulnerable adults. This leads to unjustifiably paternalistic healthcare responses that undermine patient autonomy and exacerbate their vulnerability. Third, it will be shown that common law, medical ethics and clinical practice operate on the basis that the concepts of vulnerability and autonomy are opposed.

There are three inter-related ways in which we can interpret this opposition. First, as we have already observed, it can be interpreted as a contrast between the liberal subject, who is legally recognised as able to give or express 'real and genuine consent' without additional support, and the vulnerable subject, who, on the basis of legal definition, ${ }^{5}$ is recognised as unable to give or express 'real and genuine consent' and thereby denied the opportunity to exercise their liberty at law (unless supported by a process of 'unencumbered decision-making'). Second, the opposition can be conceived as the incompatibility between a

\footnotetext{
${ }^{i i}$ Medical ethicists have also employed the concept of vulnerability to identify those who are especially vulnerable to threats to their 'dignity', 'rights' and 'capacity to live as free, autonomous individual[s]' as a result of situational features and/or their inherent characteristics. See UNESCO. The principle of respect for human vulnerability and personal integrity: Report of the International Bioethics Committee of UNESCO. Paris: UNESCO 2013. https://unesdoc.unesco.org/ark:/48223/pf0000219494.
} Accessed 11 Aug 2020. person's vulnerability and their ability to make decisions in line with their own values. Third, the opposition of autonomy and vulnerability can be viewed as a tension between promoting a vulnerable adult's autonomy and responding to their vulnerability through protective measures. As shall be demonstrated, the problem with conceiving vulnerability and autonomy in oppositional terms is that it generates healthcare interventions, including applications under the High Court's inherent jurisdiction, that not only undermine, but also violate the autonomy of capacitous vulnerable patients.

This paper argues that the concepts of autonomy and vulnerability are necessarily entwined. On that basis, the focus should be on promoting the autonomy of capacitous vulnerable adults where possible. However, in order to adequately capture the autonomy-undermining, autonomy-violating and autonomypromoting issues at stake in matters specific to capacitous vulnerable adults, the claim that the concepts of autonomy and vulnerability are necessarily entwined cannot be based solely on mental capacity considerations, standards of informed consent or processes of 'unencumbered decision-making' as traditionally employed in discussions of vulnerable adults and, more generally, patient autonomy.

\section{Problems with typical responses to vulnerability}

In order to understand how current legal and healthcare responses to vulnerability relate to a vulnerable patient's autonomy, we need to be aware that the UK policy surrounding medical decision-making and standard common law conceptions of vulnerability do not sufficiently distinguish between a patient's mental capacity and the conditions of autonomous choice and action. ${ }^{9}$ In light of section 2 of the MCA 2005, it is assumed that if a patient has the capacity to understand, retain, use and weigh the information relevant to the decision and makes and communicates that decision free from external influence, then such a decision is autonomous. The running together of mental capacity and autonomy is not a practice specific to the UK health policy and medical law. Not only has it historically formed the basis of traditional legal responses to vulnerable adults in, for example, Canada, Singapore, Germany and the Netherlands, it has been at the heart of recent debates concerning the implementation of New Zealand's End of Life Choice Act 2019, ${ }^{10}$ and is a key factor in current discussions surrounding the impact of COVID-19 on elective surgeries. $^{11}$

At least when it comes to legal responses to vulnerability in England and Wales, the problem is that although the courts perceive the facilitation of 'unencumbered decision-making' as a way of resolving the problem of the voluntariness of the decisions made by capacitous vulnerable adults, it should not be equated with the restoration of autonomy neither should it be assumed that a decision resulting from this facilitative approach is an autonomous one. According to legal scholars, the problem is that the courts have confused the concept of autonomy with the concept of liberty. ${ }^{12}$ Fulfilling the standards of informed consent should secure one's liberty to non-discriminatorily participate in the process of informed consent. However, it does not ensure that the resulting decision is autonomous. In other words, the fact that a decision is voluntary, preceded by the imparting of medically relevant information and made by an individual with the capacity to understand, retain and use that information provides no assurances that the individual has, in fact, either understood the information or rationally deliberated in a way that ensures that their decision is autonomous.

Although the conditions of autonomy are much debated in moral psychology, medical ethicists have argued that most 
plausible conceptions of autonomy identify rational deliberation as a necessary feature. ${ }^{13-16}$ Similarly, when the concept of autonomy is disambiguated from the concept of liberty, the combination of common law, statutory duties and established medical jurisprudence amounts to a legal approach to autonomy where the concern is 'not just for the capacity for reason, but also for the effective use of it' (italics added). ${ }^{12}$ What this means is that we are required to 'judge the quality of a person's exercise of autonomy by the soundness of her reasoning, given her own values'. ${ }^{12}$ Because medical law generally demands that health practitioners do not question a patient's values, desires or motives ${ }^{17}$ a patient's autonomy (or lack thereof) is judged on the basis of their exercise of reason in relation to their values, desires and motives. The problem is that the standard common law response to capacitous adults who are judged to be at risk of constraint, coercion or undue influence precludes any engagement with the rationality of the unencumbered decision-making process. For instance, as Modey J observed in A Local Authority $v$ Mrs $A$ and $M r A$ (2010), determinations regarding the voluntariness of the capacitous vulnerable adult's decision should focus solely on the effects of constraint, coercion or undue influence on the patient's ability to manage information relating to 'proximate medical issues'. ${ }^{7}$ In other words, what is not under consideration is the effect of such malign external influences on the capacitous vulnerable adult's reasoning in relation to their values, desires and motives.

Where questions of rationality and, by implication, autonomy are specifically concerned, medical law, as already noted, demands non-prejudicial deference to the values on which a patient's decision is based. ${ }^{17}$ However, legal scholars have shown that the law has developed on the back of two contradictory bases: (1) 'rational decision-making given an individual's own values'; and (2) 'rational decision-making given some objective or in principle universally acceptable values'. ${ }^{12}$ While the former standard for rational decision-making protects the autonomy of those the law takes to be non-vulnerable, the latter results in the denial of a vulnerable adult's decision-making authority in order that 'more rational' decisions are effected in their best interests. As a result, when it comes to responding to vulnerability, the principle of best interest can be employed by healthcare staff and the courts in order to over-ride the primary principle of the inherent jurisdiction, that is, to 'allow the individual to be able to regain their autonomy of decision-making. ${ }^{18} 19$ Thus, we see that where patient autonomy, as opposed to liberty, is specifically concerned, one's vulnerability is deemed to be incompatible with the ability to make medical decisions in accordance with the values that one voluntarily endorses.

As already observed, the problem that emerges when the courts interpret the purported opposition between autonomy and vulnerability as a contrast between 'the liberal subject' and 'the vulnerable subject ${ }^{20}$ is that it denies capacitous vulnerable adults the opportunity to non-discriminatorily participate in the process of informed consent. When autonomy and vulnerability are conceived as oppositional terms in such a way that a person's vulnerability is deemed to be incompatible with the ability to make decisions in line with their own values, legal interventions, and best-interests decisions resulting from those interventions, can undermine a capacitous vulnerable adult's autonomy and, simultaneously, exacerbate their overall vulnerability. For instance, if those who are deemed to be vulnerable are so because they are taken to be at risk to threats to their dignity, rights and capacity to live as free, autonomous individuals, then it has been argued that protective responses that incorporate substituted decision-making or best-interest decisions can compound rather than alleviate such threats. ${ }^{21} \mathrm{~A}$ second argument states that the denial of an individual's liberty to partake in decisionmaking processes that guard against coercion, constraint and undue influence can result in increased susceptibility to malign external influence, which not only exacerbates vulnerability, but also compromises the power an autonomous agent has over their reasoning processes such that their decisions can no longer be deemed to be autonomous. ${ }^{22} 23$

Treating vulnerability and autonomy as oppositional concepts can also lead to interventions that not only undermine, but also violate the autonomy of capacitous vulnerable adults. For instance, concerning one of the first cases in which the inherent jurisdiction was exercised in the context of medical treatment, the court heard how a National Health Service (NHS) Trust had made an urgent application for authority to remove $\mathrm{Mr}$ Mazhar, a capacitous 26-year-old with muscular dystrophy, from his home in order to treat him in hospital. ${ }^{18}$ Even though he lived with his mother and sisters, who were trained to deliver specialist care and were willing to do so, and despite explicitly stating that he did not wish to be taken to hospital, the NHS Trust claimed that staff were not available to tend to Mr Mazhar at home, his mother was not trained to provide specialist care and he was oppressively influenced by his relatives. Ultimately, the order was made for Mr Mazhar to be removed from his home and deprived of his liberty in a hospital. Recalling the facts of the case, Ryder LJ acknowledged that the Trust's claims regarding undue influence and the mother's inability to administer specialist care were both incorrect.

First, if we accept that an individual's sovereignty-the domain that protects individuals from non-consensual bodily interference-is one dimension of their autonomy, ${ }^{24-26}$ then it is clear how the denial of decision-making authority can violate the autonomy of capacitous vulnerable adults. The point is that the refusals that Mr Mazhar was denied from expressing are precisely the means by which individuals with capacity can deny permissions and exert the boundaries of their sovereign authority over their bodies. ${ }^{27}{ }^{28}$ However, even if the order violated $\mathrm{Mr}$ Mazhar's sovereignty by-contra his wishes-removing him from his home and depriving him of his liberty in hospital, one might argue that this specific violation of Mr Mazhar's autonomy and the associated denial of his decision-making authority did not directly stem from the court's perception of his autonomy as incompatible or in tension with his vulnerability. Rather, one might claim that Mostyn J made the order on the basis of the presented evidence, which (falsely) claimed that Mr Mazhar's family were unable to provide specialist care for him at a time when healthcare staff were unable to offer treatment at his home. Consequently, given that Mostyn J was not party to the agreed facts (as detailed in the High Court's judgment regarding Mr Mazhar's claim against the Lord Chancellor and the NHS Trust), ${ }^{18}$ the order may be perceived to have been made in Mr Mazhar's best interests in order to safeguard his health. Nevertheless, even if we discount the fact that, for the purposes of Article 5 (1) of the European Convention of Human Rights, a deprivation of liberty must be based on the reliable demonstration of a person's 'unsound mind', this 'bestinterest' interpretation of Mostyn J's order too easily glosses over the matter of Mr Mazhar's mental capacity. It would be unlawful for a judge to make such an order in relation to a nonvulnerable adult with capacity. It follows that as Mostyn J was aware that Mr Mazhar did have mental capacity in all material respects, including, specifically, with regard to decisions about his care, then Mr Mazhar's status as a vulnerable person would have had a bearing on Mostyn J's response to the application 
made by the NHS Trust. It is, therefore, reasonable to claim that even though the court and the healthcare staff may have been primarily concerned with acting in Mr Mazhar's best interests, they failed to recognise his normative authority to make appropriate and intelligible judgments about his own treatment. In other words, they failed to recognise his status as someone with the authority to be self-governing and self-determining, ${ }^{29}$ and this failure was ultimately, even if it was not explicitly, based on Mr Mazhar's status as a vulnerable adult. Therefore, both the application made by the NHS Trust and the resulting order under the inherent jurisdiction violated Mr Mazhar's autonomy because they precluded him from making claims to autonomy altogether. $^{30}$

Although the High Court's approach to the inherent jurisdiction does not capture the autonomy of capacitous vulnerable adults, the problem we have observed is that medical staff and the courts are required to navigate the tension between two incompatible protective obligations: (1) the duty to protect the autonomy of capacitous vulnerable adults; and (2) the duty to protect them from harms to their well-being and other interests. On the one hand, by prioritising the latter and thereby denying capacitous vulnerable adults their decision-making authority, some of the effects this can have on their autonomy are contingent in the sense that whether and to what extent the denial of decision-making authority affects a person's autonomy will depend on their individual characteristics. For example, whether a specific capacitous vulnerable adult finds herself increasingly susceptible to coercion, constraint and undue influence as a result of being denied her normative authority to make judgments about her own treatment will depend on the effects of this denial on her psychological states and dispositions, such as her selfrespect, self-esteem and self-trust, which, in part, constitute her practical identity and self-understanding (and thereby determine her values, desires, motivations and reasoning processes). ${ }^{31-35}$ On the other hand, the inherent jurisdiction generates necessary harms to the autonomy of capacitous vulnerable adults regardless of their individual characteristics and resiliency to the effects of paternalistic intervention. As the case of Mr Mazhar illustrates, succeeding in making claims to one's autonomy is impossible for one to do on one's own. Not only does it demand that healthcare staff and the courts recognise that one has the status of autonomy, it requires that they meet the prescribed uptake conditions associated with one's permissions and refusals. Therefore, when a capacitous vulnerable adult recognises herself as someone with normative authority and makes commitments and decisions on the basis of that recognition, the denial of that authority not only violates her sovereignty (when medical interventions go against her decisions), it also violates her status of, and claims to, autonomy.

Of course, one may argue that the violation of the autonomy of capacitous vulnerable individuals is the ethical price that must be paid in order to safeguard these patients from those situational and inherent risks of harm on the basis of which they are judged to be vulnerable. However, if it can be demonstrated that the concepts of autonomy and vulnerability are necessarily entwined, then an argument can be made for treating capacitous vulnerable adults the same as capacitous non-vulnerable patients and thereby seeking to promote their autonomy where possible. This will be the focus of the following section.

\section{Capturing and promoting vulnerable autonomy}

In relation to the issues of autonomy and vulnerability discussed in this paper, there are two ways in which we can interpret the claim that the concepts of vulnerability and autonomy are entwined. Both interpretations can be framed in relation to two of the ways of interpreting the opposition of autonomy and vulnerability previously mentioned: (1) as the incompatibility between a person's vulnerability and their ability to make decisions in line with their own values; (2) as a tension between promoting a vulnerable adult's autonomy and responding to their vulnerability through protective measures. Accordingly, the first way to interpret the entwinement of vulnerability and autonomy is as a compatibility relation, specifically, that a vulnerable adult's ability to make rational decisions can be compatible with their vulnerability. Second, when we say that vulnerability and autonomy are entwined, we mean that we can respond to an individual's vulnerability by, where possible, first seeking to promote their autonomy rather than by commencing with an approach that focuses solely on the duties of the courts and healthcare practitioners to protect well-being and other interests. However, neither of these interpretations sufficiently function as a plausible interpretation of the necessary entwinement of vulnerability and autonomy. When, as the rest of this paper seeks to demonstrate, we claim that the concepts of vulnerability and autonomy are necessarily entwined, we are implying that there is a relationship between the two concepts such that a person's autonomy is itself something that is vulnerable. And a person's autonomy is vulnerable precisely because whether they have the status of someone with the authority to be self-governing and self-determining, and, accordingly, whether they are able to make claims to, exercise and achieve their autonomy, is, in part, dependent on the actions of others in ways that are outside of the person's control. Nevertheless, the fact that a person's autonomy is vulnerable does not preclude the possibility that they are able to make decisions in line with their own values nor does it entail that responses to their vulnerability cannot promote their autonomy. Indeed, the vulnerability of a capacitous vulnerable adult's autonomy forms the basis of the duty to promote their autonomy where possible.

The argument that autonomy and vulnerability are necessarily entwined cannot appeal merely to mental capacity, standards of informed consent or processes of 'unencumbered decisionmaking'. First, capacitous vulnerable adults are already competent. Second, as has been demonstrated, the model of informed consent is incompatible with vulnerability precisely because the law deems the voluntariness of decisions made by capacitous vulnerable adults to be at risk. Third, not only is the facilitation of 'unencumbered decision-making' not to be confused with the restoration of autonomy, the success of 'unencumbered decisionmaking' is not something that a vulnerable adult can control. For example, assuming that the goal is for capacitous vulnerable adults to fulfil the standards of informed consent, we must acknowledge that the practice of informed consent does not just require a capacitous adult patient to communicate a voluntary decision having been sufficiently informed of the material treatment risks. As the case of Mr Mazhar demonstrates, successful participation in-what we might call-an economy of consent depends on the recognition of the patient's permissions and refusals as those made by individuals who take themselves to have the status of autonomy. Thus, what is important in the context of medical decision-making involving capacitous vulnerable patients is consideration of the ways in which relational practices of recognition undermine, violate, preserve or enable the patient's authority to give permissions and refusals.

As theorists of autonomy have acknowledged, there is a normative element to the idea of taking oneself to have the status of autonomy. ${ }^{29-33} 3637$ To take oneself to be someone with the authority to be self-governing and self-determining, that is, 
to self-authorise one's autonomy, then one must view oneself as a 'legitimate source of reasons for acting'. ${ }^{31}$ In other words, one must view one's normative authority as warranted or deserved. ${ }^{30}$ For instance, I must recognise that I am in control of my values, desires and motivations rather than being in the grip of some desire that has been thrust on me by a malign external influence. ${ }^{37}$ In turn, once one takes one's authority to be legitimate, then one accepts that one is able to speak for oneself and thereby answer to others. 333637

In laying out the basis of the first-person conditions for autonomy, we can see that viewing oneself as having legitimate authority to make decisions on the basis of one's values bridges the gap between autonomy and liberty in medical law. Specifically, self-authorisation includes the idea that patients have the right to protect their domain of sovereignty by expressing their permissions and refusals. ${ }^{38}$ Therefore, unlike the model of informed consent, which, as we have seen, excludes those who have been identified as vulnerable precisely because the voluntariness of their decisions is deemed to be at risk, the status of being normatively authoritative should not be conceived as opposed to vulnerability in principle. The point is that even though I am vulnerable and, therefore, on the basis of legal definition, deemed unable to consent according to standards of voluntariness, I recognise myself as someone who has the status of being an autonomous individual. I recognise that I have the level of competence as well as the legitimacy necessary to make my own decisions regarding my care and treatment. Ultimately, from an autonomy perspective, I understand myself to be no different to capacitous patients who the law deems to be non-vulnerable.

At the same time, even though a vulnerable patient may legitimately take herself to have the normative authority to make decisions about her own treatment and, simultaneously, to assert the boundaries of her sovereignty, ${ }^{18} 19$ the fact that she recognises that she is able to speak for herself means that her claims to autonomy, including the resulting decisions regarding her care and treatment, are open to dispute. After all, as autonomy theorists acknowledge, self-authorisation implies that autonomy is anathema to insulating oneself from critique. ${ }^{36-38}$ It follows that on this approach, autonomy is not just normative, but also intersubjective. As already demonstrated with regard to the case of Mr Mazhar, and as we also observe in Ms B $v$ An NHS Hospital Trust (2002), ${ }^{19}$ a capacitous vulnerable patient cannot determine whether the decisions she makes regarding her care and treatment will be respected. When giving permissions and refusals in relation to specific healthcare interventions, the capacitous vulnerable patient is appealing to clinical practitioners and the courts for recognition of her legitimate authority to make her own decisions regarding her care and treatment in line with her own values, motives and desires. In the absence of such recognition, the concrete status of her autonomy remains open to dispute and it will be impossible to guarantee the desired outcomes of her decisions.

When we combine the normative and intersubjective elements, what results is a conception of legitimate, self-authorised autonomy that is necessarily dependent on interpersonal recognition, specifically, and in the first instance, the recognition of healthcare practitioners and, if this recognition is not granted, the recognition of the court to which an application has been made. We might call this an account of vulnerable autonomy because, in this instance, the vulnerable patient's autonomy is vulnerable to the denial of legitimate recognition. However, we cannot limit this specific kind of vulnerability by appealing solely to standards of informed consent or processes of 'unencumbered decision-making'. First, as previously shown, the process of 'unencumbered decision-making' should not be equated with the restoration of autonomy of decision-making. Second, reliance on informed consent as the primary mechanism for allowing patients to make decisions regarding their care and treatment can, when employed with capacitous vulnerable adults, undermine their autonomy by compromising their ability to make decisions on the basis of their own values, motives and desires. Third, because the model of informed consent is incompatible with vulnerability, its employment violates the autonomy of vulnerable patients by precluding them from making claims to autonomy and asserting the boundaries of their sovereignty. What this account of legitimate, self-authorised autonomy demonstrates is that when capacitous vulnerable adults are denied their decision-making authority by healthcare practitioners and the courts, this is not because their vulnerability necessarily stops them from being able to make autonomous decisions regarding their care and treatment. Rather, it is because the model of informed consent and the standards of rational decision-making in common law cannot adequately capture the autonomy of capacitous vulnerable adults.

The question of how this conception of self-authorised autonomy might be operationalised in a common law context is complex. At least at this stage, we need not be preoccupied with providing an answer if we accept the reasonable claim that successfully employing this approach to vulnerable autonomy in a clinical context should, in principle, reduce the number of applications for pre-emptive, protective intervention made by healthcare providers to the High Court in matters relating to vulnerable adults with capacity. Although it is not the purpose of this paper either to clarify a set of standards and procedures for respecting the autonomy of capacitous vulnerable adults or to provide a comprehensive set of recommendations for linking this duty to current safeguarding frameworks focused more on protecting vulnerable patients from harm, there are three important features of any proposed framework that seek to apply the concept of self-authorised autonomy to clinical decisionmaking situations involving vulnerable adults with capacity.

First, if the patient chooses not to defer the care or treatment decision to healthcare practitioners, then she will need to recognise whether she has the authority to exercise her autonomy in making the specific care or treatment decision. In short, she will need to determine whether she is a legitimate source of the reasons for her specific care or treatment decision, that is, whether the reasons on which her decision is based are her own values, desires and motives or whether these reasons are the results of coercive, manipulative or oppressive influence. If the patient is unable to take herself to be a legitimate source of reasons for acting, and if support from, for example, healthcare staff, social care staff or her family cannot help her overcome any barriers stopping her from successfully identifying her own values, desires and motives, then there is a reasonable basis for adopting a more protective approach, including, if applicable, an application under the inherent jurisdiction.

Second, if the patient is able to recognise herself as having legitimate authority to make her own decisions regarding her care and treatment, then, bearing in mind that self-authorised autonomy implies that one is able to speak for oneself and thereby answer to others, she should be disposed to answer for that decision. In other words, she should be disposed to demonstrate that her treatment decision coheres with her own values, motives or values.

Third, on the basis that a vulnerable patient's autonomy is intersubjectively dependent, her legitimate authority to make her own decisions regarding her care and treatment should be 
recognised by healthcare practitioners thereby securing her status as an autonomous individual. If such recognition is granted by healthcare staff, then there is no autonomy-based reason not to respect her decision, including her permissions and refusals regarding specific care or therapeutic interventions.

For any framework that employs the concept of self-authorised autonomy to promote the autonomy of capacitous vulnerable adults, there is the requirement for healthcare providers and the courts to provide the opportunity for vulnerable patients and the clinicians involved in the decision-making process to fulfil the aforementioned conditions before any pre-emptive duties of protection are effected. Some practitioners may be satisfied to recognise a vulnerable patient as someone with the status of autonomy without requiring the patient to substantively demonstrate the legitimacy of her normative authority. However, if one of the aims of promoting the autonomy of capacitous vulnerable adults is to avoid legal interventions that can lead to the denial of decision-making authority and the violation of autonomy, then greater focus should be placed on the notion of answerability that is bound up with the concept of self-authorised autonomy. For instance, in order to grant legitimate recognition to a vulnerable patient, the attending clinical practitioner may consider it appropriate for the patient to detail her values, desires and motives and to demonstrate that her treatment decision is in line with those motivating attitudes. Bearing in mind that the patient's status as a vulnerable individual means that they are at greater risk of constraint, coercion or undue influence, then this process may require additional support and careful, yet detailed, questioning on the part of healthcare staff in order to successfully identify the source of the patient's reasons for her decision and to ensure that her decision coheres with those reasons. ${ }^{\text {iii }}$ Of course, one might object that the proposed response to the vulnerability of a capacitous patient is paternalistic. In response, we can concede that an approach that requires vulnerable patients to fulfil the aforementioned conditions may seem more paternalistic than standard approaches to respecting the autonomy of nonvulnerable patients with capacity. Nevertheless, the autonomy of non-vulnerable patients is not what is at stake in these discussions. Moreover, the approach to promoting the autonomy of capacitous vulnerable patients presented here is less paternalistic than current responses to vulnerability in healthcare and common law, which, as we have seen, not only undermine the autonomy of capacitous vulnerable adults, but also violate their sovereignty as well as their claims to, and status, of autonomy.

Given that typical responses to vulnerability include the duty to protect vulnerable adults from harms to their well-being and other interests, one may object to this attempt to capture and promote the autonomy of capacitous vulnerable adults for two reasons. First, it might be argued that such an approach disregards those capacitous vulnerable adults who wish to defer decisions or who believe that the purported harms to their well-being and interests are more of a concern than the harms to their autonomy that result from applications under, and exercises of, the inherent jurisdiction. In response, we should recall the claim that the necessary entwinement of the concepts of autonomy and vulnerability can support the argument for promoting the autonomy of capacitous vulnerable adults where possible. It follows that such an approach does not demand that

\footnotetext{
iii It should be noted that in order to avoid discriminating against the patient on the basis of her vulnerability, healthcare practitioners should non-prejudicially defer to the values on which her decision is based (the standard of rationality already employed to protect the autonomy of non-vulnerable patients).
}

all capacitous vulnerable patients always be granted privileged authority to choose, permit or refuse specific medical and carebased interventions where they concern them. Rather, on the basis that a capacitous vulnerable patient's autonomy is intersubjectively dependent, she should be recognised as having the status of someone with the authority to make medical decisions regarding her care and treatment if she is the legitimate source of the reasons for her decision and that decision is rational in the sense that it is line with own values, desires and motives. So long as the vulnerable patient has the status of someone with the legitimate authority to be self-governing and self-determining, she should be afforded the opportunity to express her choice, including the choice to defer to the courts and/or practitioners, before any pre-emptive duties of protection are effected. Even if critics concede that point, they might argue that the proposed approach to vulnerable autonomy still disregards certain groups of capacitous vulnerable adults, specifically, those in lifethreatening situations where the situational and/or inherent risks of harm to their well-being significantly outweigh any purported harms to their autonomy. There are, it seems, two responses to this objection. First, if there is, in fact, an immediate and significant threat to life, then it is highly unlikely that the patient will be in a position to authorise her status as an autonomous agent let alone be in a position to vouch for her normative authority as warranted or deserved. Second, in life-threatening emergency situations, there is no plausible reason to treat capacitous vulnerable adults any differently from capacitous non-vulnerable patients. For instance, when medical ethicists argue that in emergency situations, the principle of respect for patient autonomy should be over-ridden in order to reduce harm and improve health statuses, arguments for such an approach should, in principle, cover both non-vulnerable and vulnerable patients.

\section{CONCLUSION}

This paper attempts to address the problems with current legal and clinical responses to vulnerability, particularly when they concern vulnerable adults with capacity. Ultimately, common law approaches to restoring autonomy of decision-making fail to adequately capture the autonomy of capacitous vulnerable patients due to problems with the model of informed consent and the presence of incompatible standards of rational decisionmaking at law. Healthcare and legal responses to vulnerability that are predicated on the opposition between autonomy and vulnerability not only undermine the autonomy of capacitous vulnerable adults, but also violate their sovereignty as well as their claims to, and status, of autonomy. Conceptualising autonomy and vulnerability as necessarily entwined not only gets around inconsistent common-law claims regarding the autonomy of vulnerable adults, it provides practitioners and the courts with a normative basis for navigating the tension between their incompatible protective duties by seeking to promote autonomy where possible.

Acknowledgements The author is immensely grateful to John McMillan and the two anonymous reviewers for their detailed and critical responses to this article. He also wishes to thank Arnel Delima for facilitating the timely review of the submission.

Contributors $J \mathrm{~L}$ is the sole contributor to all aspects of the research process, including the drafting, writing and revision of the manuscript.

Funding The authors have not declared a specific grant for this research from any funding agency in the public, commercial or not-for-profit sectors.

Competing interests None declared.

Patient consent for publication Obtained. 
Provenance and peer review Not commissioned; externally peer reviewed.

Data availability statement All data relevant to the study are included in the article

ORCID iD

Jonathan Lewis http://orcid.org/0000-0001-8342-1051

\section{REFERENCES}

1 Dunn MC, Clare ICH, Holland AJ. To empower or to protect? Constructing the 'vulnerable adult' in English law and public policy. Legal stud. 2008;28(2):234-53.

2 Keywood K. Safeguarding reproductive health? the inherent jurisdiction, contraception, and mental incapacity. Med Law Rev 2011;19(2):326-33.

3 DL v A Local Authority. EWCA Civ 253, [2012] CPLR 504; 2012.

4 . London Borough of Croydon v KR \& Anor [2019] EWHC 2498 (Fam); 2019.

5 Re SA (Vulnerable Adult with Capacity: Marriage) [2005] EWHC 2942 (Fam), [2006] 1 FLR 867.

6 LBL V RYJ and VJ [2010] EWHC 2665 (COP)

7 A Local Authority v Mrs A and Mr A [2010] EWHC 1549 (Fam) (COP).

8 Rose E, Doyle P. Newsflash: Emergency application to the High Court's inherent jurisdiction to protect a vulnerable adult. Available: https://www.hempsons.co. uk/news-articles/newsflash-emergency-application-to-the-high-courts-inherentjurisdiction-to-protect-a-vulnerable-adult/ [Accessed 11 Aug 2020].

9 Herring J, Wall J. Autonomy, capacity and vulnerable adults: filling the gaps in the mental capacity act. Legal stud. 2015;35(4):698-719.

10 Tsai BC, Menkes DB. New Zealand doctors and euthanasia-legal and practical considerations of the end of life choice act. N Z Med J 2020;133(1522):149-60.

11 Harkin DW. Ethics for surgeons during the COVID-19 pandemic, review article. Ann Med Surg 2020:55:316-9.

12 Coggon J, Miola J. Autonomy, liberty, and medical decision-making. Camb Law J 2011;70(3):523-47.

13 Savulescu J, Momeyer RW. Should informed consent be based on rational beliefs? J Med Ethics 1997;23(5):282-8

14 Holroyd J. Relational autonomy and Paternalistic interventions. Res Publica 2009;15(4):321-36.

15 Schaefer GO, Kahane G, Savulescu J. Autonomy and enhancement. Neuroethics 2014; 7:123-36

16 Lewis J. Autonomy and the limits of cognitive enhancement. Bioethics 2020;0:1-8.

17 Montgomery v Lanarkshire Health Board [2015] UKSC 11, [2015] 1 AC 1430.

18 Mazhar v Lord Chancellor [2017] EWHC 2536 (Fam), [2018] Fam 257.

19 Ms B v An NHS Hospital Trust [2002] EWHC 429 (Fam), [2002] 1 FLR 1090.
20 Mackenzie C, Rogers W, Dodds S. What is vulnerability and why does it matter for moral theory? In: Mackenzie C, Rogers W, Dodds S, eds. Vulnerability: new essays in ethics and feminist philosophy. Oxford: Oxford University Press, 2014: 1-29.

21 Mackenzie C. The importance of relational autonomy and capabilities for an ethics of vulnerability. In: Mackenzie C, Rogers W, Dodds S, eds. Vulnerability: new essays in ethics and feminist philosophy. Oxford: Oxford University Press, 2014: 33-59.

22 Rogers W. Vulnerability and bioethics. In: Mackenzie C, Rogers W, Dodds S, eds. Vulnerability: new essays in ethics and feminist philosophy. Oxford: Oxford University Press, 2014: 60-87.

23 Dodds S. Dependence, care and vulnerability. In: Mackenzie C, Rogers W, Dodds S, eds, Vulnerability: new essays in ethics and feminist philosophy. Oxford: Oxford University Press, 2014: 181-203.

24 Archard D. Informed consent: autonomy and Self-Ownership. J App/ Philos 2008;25(1):19-34.

25 Walker T. Respecting autonomy without disclosing information. Bioethics 2013:27(7):388-94.

26 Lewis J. Getting obligations right: autonomy and shared decision making. J App/ Philos 2020:37(1):118-40.

27 Hornsby J, Langton R. Free speech and Illocution. Legal Theory 1998;4(1):21-37.

28 Maitra I, McGowan MK. On silencing, rape, and responsibility. Australas J Philos 2010:88(1):167-72.

29 Mackenzie C. Responding to the agency dilemma: Autonomy, adaptive preferences, and internalized oppression. In: Oshana M, ed. Personal autonomy and social oppression. New York: Routledge, 2015: 48-67.

30 Anderson J. Autonomy and vulnerability entwined. In: Mackenzie C, Rogers W, Dodds S, eds. Vulnerability: new essays in ethics and feminist philosophy. Oxford: Oxford University Press, 2014: 134-61.

31 Anderson J, Autonomy HA. vulnerability, recognition, and justice. In: Christman J, Anderson J, eds. Autonomy and the challenges to liberalism: new essays. Cambridge: Cambridge University Press, 2005: 127-49.

32 Benson P. Feminist intuitions and the normative substance of autonomy. In: Taylor JS, ed. Personal autonomy: new essays on personal autonomy and its role in contemporary moral philosophy. Cambridge: Cambridge University Press, 2005: 124-42.

33 Mackenzie C. Relational autonomy, normative authority and perfectionism. J Soc Philos 2008;39(4):512-33.

34 Govier T. Self-Trust, autonomy, and self-esteem. Hypatia 1993;8(1):99-120.

35 McLeod C. Self-trust and reproductive autonomy. Cambridge, MA: MIT Press, 2002.

36 Anderson J. Autonomy and the authority of personal commitments: from internal coherence to social normativity. Philos Explor 2003:6(2):90-108.

37 Westlund AC. Rethinking relational autonomy. Hypatia 2009;24(4):26-49.

38 Westlund A. Relational autonomy and practical authority. In: Garavaso P, ed. The Bloomsbury companion to analytic feminism. London and New York: Bloomsbury, 2018: 375-93. 